\section{Daily life for chronically ill oldest old persons}

\author{
Aud Moe, ${ }^{1,2}$ Ingela Enmarker, ${ }^{1}$ \\ Ove Hellzén ${ }^{1,2}$ \\ 'Faculty of Health and Science, \\ Nord-Trondelag University College, \\ Norway; ${ }^{2}$ Department of Health Sciences, \\ Mid Sweden University, Sweden
}

\section{Abstract}

In the past, the study of old age often focused on the losses and problems associated with ageing. In recent times, the focus has been on the positive aspects, such as quality of life, inner strength, and enjoying life. The aims of this study were to highlight the ways in which chronically ill older persons experience the meaning of daily life and to understand what it means to live at home with chronic disease. In-depth interviews were used to illustrate individual experiences. The sample consisted of 13 chronically ill persons, aged 80 to 94 years, living at home and receiving assistance in the form of home nursing care. Data were analyzed using the phenomenological hermeneutical method. After a naïve reading and a structural analysis of the text, we identified three themes: being insufficient, becoming dependent, and enjoying life. The comprehensive understanding suggested that daily life involved bad days, described as illness with dysfunctions, limited energy, and dependency on others. Daily life also had its positive aspects, described as enjoying life. Dignity was threatened by feelings of being a burden to others and was affirmed by experiencing a will to live. It was concluded that bad days with experiences of suffering and good days that provided the older with experiences of enjoying life could help them meet adversity through qualities of resilience that gave meaning to daily life and helped them to think positively in times of greater difficulty.

\section{Introduction}

All European countries are facing a growing older population. ${ }^{1}$ One challenge to consider might be ageism, which denies older people the rights and opportunities available to others. Another challenge might be the risk of functional impairment and chronic disease, which increasingly accompany old age. ${ }^{2}$ Traditionally, being old and being chronically ill have been viewed as negative factors, the focus being on the various losses and associ- ated problems. ${ }^{3,4}$ More recently, however, research into old age has identified more positive aspects. ${ }^{5-8}$ This is part of a larger study focusing on the perspective of chronically ill older persons. It attempts to illustrate the ways in which the older chronically ill living at home experience the meaning of their daily lives.

\section{The homes of older persons}

The home may be a place that offers feelings of belonging, identity and safety. It might also, however, be a place of fear and abuse, and it may invoke feelings of imprisonment. ${ }^{9,10}$ In the case of specially adapted homes, many older people were satisfied with the common areas and alarm system. They experienced feelings of autonomy and safety, took part in social activities, and had positive quality of life experiences. ${ }^{11,12}$ According to Dahlin-Ivanoff et al., ${ }^{13}$ the home was a central place in life where older people spent most of their time.

\section{Older and chronically ill persons}

Many studies have focused on specific chronic diseases. ${ }^{14-17}$ Kleinman ${ }^{18}$ differentiated between the notions of disease as described from a medical perspective and illness as a daily life experience. The daily life experience of chronic illness might be explored through several themes, such as loss, threat to identity, ${ }^{19}$ and physical changes to the body. ${ }^{20}$ Adjustment and adaptation have been studied in individual cases of the chronically ill. ${ }^{21}$ Adjustment can be seen in terms of resilience, a process whereby the individual bounces back from adversity and gets on with life. ${ }^{22}$ Staudinger et al. ${ }^{23}$ found that resilience in old age was characterized by flexibility and the ability to adjust to change. Illness might also be associated with themes such as quality of life, ${ }^{24}$ hope,${ }^{25}$ optimism, well-being, ${ }^{26}$ and inner strength. ${ }^{27}$

\section{Inner strength among the oldest old}

Nygren et al. ${ }^{27}$ focused on the inner strength shown by older persons and found that these individuals possessed inner strength at least as strong as that shown by the young. Other studies discovered that enjoying life was important in old age. ${ }^{28-30}$ In the case of the chronically ill, Delmar et al. ${ }^{31}$ found that maintaining harmony within oneself could involve moving toward a
Correspondence: Aud Moe, Faculty of Health Science, Nord-Trøndelag University College, Serviceboks 2501, N-7729 Steinkjer, Norway. Tel. +47.911.31.163 - Fax: +47.740.22.501.

E-mail: aud.moe@hint.no

Key words: chronically ill, hermeneutical, home nursing care, phenomenological.

Contributions: this study was carried out in MidNorway. AM conducted the interviews, transcribed and analyzed the text, and wrote the manuscript. IE and $\mathrm{OH}$ read the transcriptions of the interviews and supervised the research process from the planning of the study through to the data collection and analysis. $\mathrm{OH}$ and IE supervised the writing process. All authors read the final version of the manuscript.

Conflict of interests: the authors declare no potential conflict of interests.

Acknowledgments: the authors would like to thank the clients who participated in this study, and also the home nursing care services of the Mid-Norway health region. The study was supported by Nord-Trøndelag University College (project n. 24006).

Ethical approval for the study was obtained from the Mid-Norway Regional Committee of Research Ethics (4.2007/257). Data collection followed the guidelines of the Data Inspectorate of Norway (19028).

Received for publication: 19 September 2011. Revision received: 12 March 2012.

Accepted for publication: 12 March 2012.

This work is licensed under a Creative Commons Attribution NonCommercial 3.0 License (CC BYNC 3.0).

(C) Copyright A. Moe et al., 2012

Licensee PAGEPress, Italy

Nursing Reports 2012; 2:e8

doi:10.4081/nursrep.2012.e8

form of acceptance of the chronic illness, reconciled by the existence of hope and enjoying life.

Much research has been carried out on old people and on the way they adapt to change, but there has been little focus on daily life from the perspective of those who are both the oldest old and chronically ill. This phenomenological hermeneutical study aims to add to the debate about what it means to be among the oldest old and chronically ill, and to understand illness on the basis of their daily lives, particularly given that this can compromise personal human dignity. ${ }^{32}$

The study attempts to illustrate the way the oldest old and chronically ill persons experience the meaning of their daily lives, in order to understand what it means to live at home with chronic disease. 


\section{Materials and Methods}

A broadly hermeneutic phenomenological approach was chosen. The daily life experience of older persons can be captured by allowing them to describe it, since most people open up when they talk about their lives. ${ }^{33}$ This study focuses on these experiences, using narrative interviews to understand the meaning of daily life that is often taken for granted. ${ }^{34}$ The data obtained can be interpreted through a hermeneutic circle which shows movements between the understanding grasped by the reader and the meanings suggested by the text. ${ }^{35}$

\section{Data collection}

Study aims required data to be collected by interviewing oldest old persons with a variety of diagnoses and dysfunctions that would potentially illustrate a number of the challenges of living with chronic illness.

Inclusion criteria for this study were: aged 80 years or older, living at home with chronic disease, receiving help from home nursing care, and ability to confirm their consent to take part in the study. A study sample of men $(n=8)$ and women $(n=5)$, aged $80-94$ years (mean 88 years), living at home and residing in Mid-Norway, participated in this study. The participants had diagnoses such as stroke, chronic obstructive airway disease, cancer, heart disease, diabetes, and vision and hearing impairments. They had dysfunctions in basic and instrumental Activities of Daily Living (ADL), ${ }^{36}$ and they received assistance from home nursing care, which provided treatments like medication and wound care, and basic ADL. Some needed help only with medication while others required comprehensive care in all functions of ADL. They lived in either a traditional home environment or sheltered housing. Two of the participants who lived in traditional home environments were married and shared their homes with their wives. All of the subjects were capable of being interviewed. Characteristics of study subjects are shown in Table 1.

The individual narrative interviews were carried out in the participants' homes by the first author. The participants began by providing a brief description of those events that had been significant in their lives. The interviews were structured in the form of a conversation, supported by an interview guide. The initial question was Can you please tell me about your experience of living with chronic illness? The second question was How is your daily life? Follow-up questions were asked when necessary. The order of the questions varied,

Table 1. Study subjects gender, age, assistance from home nursing care and living arrangements.

\begin{tabular}{lccc} 
Gender & $\begin{array}{c}\text { Age } \\
\text { (years) }\end{array}$ & Home nursing care & living arrangements \\
F & 88 & Once a week & Alone, sheltered housing \\
F & 85 & 2 times a day & Alone, sheltered housing \\
\hline F & 91 & 2 times a day & Alone, traditional home \\
F & 94 & 2 times a day & Alone, traditional home \\
\hline F & 91 & $4-6$ times a day & Alone, sheltered housing \\
M & 81 & Once a week & With his wife, traditional home \\
\hline M & 93 & Once a week & Alone, traditional home \\
M & 91 & Once a day & Alone, sheltered housing \\
\hline M & 80 & 2 times a day & Alone, traditional home \\
M & 86 & 2 times a day & Alone, sheltered housing \\
\hline M & 89 & 2 times a day & Alone, sheltered housing \\
M & 89 & 2 times a day & Alone, sheltered housing \\
\hline M & 87 & 6 times a day & With his wife, traditional home \\
\hline
\end{tabular}

depending on how the conversation developed. Some interviews were completed in one visit and others in two, depending on the condition of the participant. Each interview was taperecorded and lasted 60-90 min.

\section{Data analysis}

The tape-recorded interviews were transcribed word for word. The transcribed text was then compared with the tape-recorded interview and adjusted accordingly. ${ }^{37}$ Transcriptions of the interviews were carried out in confidence, without the addition of personal information about the individuals concerned. The second and third authors then read through the texts. In considering our findings, we made use of the transcriptions rather than the audiotapes. We then reached consensus through reflection and discussion. ${ }^{38}$

The authors analyzed the transcribed text in three steps: ${ }^{37}$ first reading, structural analysis, and comprehensive understanding of the dialectic movements between the understanding and explanation. This was influenced by the researchers' prior understanding, as all of the researchers are nurses. The first author who collected data had professional experience as a geriatric nurse. Prior understanding could affect data not only through the questions that were asked, but also through the observations made during the interviews. The researchers tried to use this factor in a positive way, i.e. observing the capacity of the interviewee and his or her willingness to be interviewed.

\section{First reading}

The first reading of the interviews was regarded as a naïve reading of the interview text and was used to formulate the older per- son's perspective of daily life in terms of living with old age and chronic illness. The first reading was naïve in that the text was reviewed several times in as non-critical and openminded a way possible in order to allow the text to speak to us and allow us to gain a general sense of the meaning of its content as expressed by each respondent and formulated by us from a phenomenological perspective. The initial understandings gained from this first (naive) reading then had to be validated using structural analysis.

\section{Structural analysis}

The text was read again line by line and sorted into meaning units that were considered in terms of the aim of the study and the naïve understanding of the text. These meaning units were condensed to descriptions formulated in everyday language. Condensed units were read through, considered in relation to similarities and differences, and then sorted. Similarly, condensed meaning units were then further condensed before being formulated into sub-themes and themes (Table 2). Themes were considered in relation to the naïve understanding of the text. We found that the themes validated this naïve understanding.

\section{Comprehensive understanding}

The text was read again as a whole, now in the light of the understanding obtained from the naïve reading, as validated by the structural analysis, and in the light of the authors' prior understanding reached by means of a theoretical framework. The reader then revised and went into the meaning of the text in more detail and looked for a meaning which could illustrate the phenomenon in question. ${ }^{39}$ This method combined phenomenological phi- 
Table 2. Example of the analytical process.

\begin{tabular}{|c|c|c|c|}
\hline Meaning units & Condensed meaning units & Sub-theme & Theme \\
\hline $\begin{array}{l}\text { Feel so good in myself when I am not ill. } \\
\text { It can then be different on bad days when I feel ill. }\end{array}$ & Do not feel good when I am ill. & $\begin{array}{l}\text { Feeling ill } \\
\text { Feeling impaired }\end{array}$ & Being insufficient \\
\hline $\begin{array}{l}\text { I see so much I want to do but cannot manage because } \\
\text { my fingers are no good. }\end{array}$ & $\begin{array}{l}\text { So much I want to do but cannot manage. } \\
\text { Feeling impaired. }\end{array}$ & & \\
\hline I need to have help from the nurses if I go to the toilet. & I need to have help to go to the toilet. & & Becoming dependent \\
\hline $\begin{array}{l}\text { I do not walk upstairs any longer; go up but not downstairs; } \\
\text { my knees are bad. I have a bedroom on the ground floor. }\end{array}$ & I have a bedroom on the ground floor now. & Staying in their homes & Enjoying life \\
\hline $\begin{array}{l}\text { I feel grateful for getting up in the morning, walking to the } \\
\text { bathroom, and caring for myself. That is the main thing. }\end{array}$ & $\begin{array}{l}\text { I'm grateful for getting up in the morning and } \\
\text { caring for myself. }\end{array}$ & Feeling grateful & \\
\hline $\begin{array}{l}\text { Then there is bingo every Monday night. } \\
\text { It is not a big thing, but we spend time together. } \\
\text { That is the important thing. }\end{array}$ & Playing bingo is mostly for having company. & Feeling alive & \\
\hline
\end{tabular}

losophy with hermeneutic interpretation in a dialectic process that moved back and forth between understanding and explanation, and that culminated in a comprehensive understanding ${ }^{40}$ arising from a circular process.

\section{Ethical considerations}

Permission to carry out the research was granted by the Mid-Norway Regional Committee of Research Ethics (4.2007/257). Data collection followed the guidelines of the Data Inspectorate of Norway (19028). The subjects were recruited by the home nursing care staff who received written information about the project. In compliance with regulations concerning confidentiality, the nurses evaluated each potential interviewee in order to ascertain his or her mental capacity to be interviewed. The nurses informed the participants about the purpose of the study, the possibility of retiring from the study at any time, the confidentiality of the study, and how the information from the interview would be used. The participants gave written consent to participate in the study before the interviews started. Because the very oldest old pesons might have felt themselves under pressure to participate in this study (since they were dependent on the home nursing care staff), the first author attempted to appraise the willingness of the participants before and during each interview. All study subjects confirmed their willingness to take part.

\section{Results}

\section{Naïve reading}

The naïve reading showed that the old and chronically ill interviewees described their daily life in terms of suffering from illness, reduced functions and limited energy. These factors meant they were not able to cope with their daily life activities or those activities connected with their illness. They felt dependent on others for treatment of their disease, for their daily activities, and for social contact. Sometimes they felt their dignity was violated. Their daily life also had its positive aspects, as they enjoyed life when they were able to stay at home, felt grateful for what they had, and experienced moments that made them feel alive.

\section{Structural analysis}

The structural analysis resulted in three themes that illustrated daily life for the old and chronically ill: being insufficient, becoming dependent, and enjoying life. These themes will be presented with their sub-themes.

\section{Being insufficient}

For these older persons persons, daily life was viewed as being insufficient because their illnesses required treatment. They were not able to cope with their activities, and some of them entertained thoughts of ending their lives. These feelings were described as feeling ill and impaired.

\section{Feeling ill}

For these interviewees, being insufficient was associated with feeling ill. Illness meant medical treatment, hospital stays, and thoughts of ending their lives. Feeling ill could mean living in an unpredictable situation with a condition that could vary from day to day and that, in turn, meant difficulties in planning because the disease could enter an active phase. For example, one of the female participants related how she had been planning to celebrate her $85^{\text {th }}$ birthday, but then she became acutely ill and had to go to hospital instead. These individuals were unable to look forward to important events free of uncertainty.

Feeling ill could involve treatment for diseases requiring medication. As 91-year old Phyllis said: Some of it is for breathing, some for my heart, and some ... I don't know what it is for, nine in the morning and six in the evening. The side effects of the medications and the need for help in taking the medications could also limit the activities of these older persons. Some needed hospital treatment; for example, a hospital visit for treatment in the form of cytotoxic therapy was described by 85 -year old Anna as follows:

... I was waiting for a long time. Then I threw up, I was so sick, in the hall ... I got sick and threw up all over... I felt so alone ... in such situations; then you feel terrible.

A visit to the hospital could be a trial; this woman could not move when she wanted to because of her illness, and that made her feel abandoned, unworthy, and nervous about receiving further treatment.

Another aspect of feeling ill could mean thinking about the last stage in life and having a number of feelings about death. Eighty-six year old Charles thought repeatedly about death: I wonder when death is coming. I'm anxious about being buried in the ground and then swallowed up in it. This fear might have been prompted by the fact that the subject of death was rarely discussed. Talking about death might make it less frightening, as 91year old Phyllis, who has a serious illness told us; she had been talking about death with her doctor and nurses, and she was confident about her own situation.

\section{Feeling impaired}

Being insufficient could involve physical, vision, or hearing impairments. Some persons, for example, had lost dexterity in their fingers, had pain in their knees, and suffered from dizziness and poor balance. When they wanted to pursue activities such as washing windows, gardening, or reading, they could not manage them. Activities that had given meaning to their daily lives in the past were expressed as having been lost. 
Feeling impaired also meant that these persons had limited energy. Taking part in activities was difficult, and sometimes there was a gap between the desire to carry out activities and the ability to do so. In the morning, for example, they would plan to do certain activities, but when they started, they could only manage half. One person felt tired and listless, which also resulted in a feeling of limited energy. Illness combined with ageing also meant that interviewees spent more time completing some activities than they had in the past; in other words, tasks that they were able to complete in a shorter time earlier in their lives now took them longer. Disease could bring on this feeling, and 89-year old Carl, who had chronic obstructive airways disease, described it; I get so tired; it is a strain with all this phlegm, and I get so exhausted. He often had to rest and was sometimes too tired to participate in activities.

Feeling impaired could mean the interviewees were shaky and unsteady on their feet, and unable to do housework or move about without using a Zimmer frame (a walker). Sometimes they overestimated what they could do on their own, did not wait for help, took risks, and fell, resulting in fractured bones and other new forms of impairment.

\section{Becoming dependent}

These chronically ill persons could not manage many tasks because of their reduced functioning, a result of their illnesses and becoming dependent on others for help. Sometimes they needed help from the family; other times, they needed help from home nursing care staff.

Becoming dependent could involve needing help and support from family in the form of practical tasks like shopping, help with the laundry, cleaning the house, or cooking dinner. These older persons reported that it felt strange to watch others straightening out their houses. Visits and phone calls kept them from feeling alone, and support from family in terms of practical work, social contact, and family ties made them feel dependent, yet also able to contribute something to the relationship.

Needing help from family could mean that older persons needed somebody to stay with them in order for them to continue living at home. Eighty-seven year old William, who needed comprehensive care, said:

If I didn't have her [his wife], I would not have been able to stay here. It is because of her that I am alive ... I am grateful that I can stay at home, and she [his wife] can still sleep next to me in the same bed... She should not have to become so tired, but this is a painful subject...there is no place like home.

When family support became necessary in order for them to stay at home, older persons had to decide between becoming a burden to their families and moving into an institution.
Needing help from home nursing care staff could involve contact with the outside world, and it meant that the older persons looked forward to such visits if the nurses had time to talk to them. This could be therapeutic for them and could put them in a good mood. Needing help from home nursing care staff could mean assistance with their treatment and personal care. This could be in the form of help with their intimate personal care; as 86-year old Charles said, I am alive, but I don't have control over certain things. So I have to wear nappies. He was losing control over his bodily functions and was, therefore, dependent on help from others. However, he felt threatened by this intimate type of care and consequently felt an underlying sense of vulnerability.

Sometimes, when the nurses were busy, the participants received help in a way they did not appreciate, and they felt they were a burden to the nurses. It was important for them not to be a burden; as 94-year old Linda put it: I fell on the bathroom floor but managed to drag myself to the living room so that it would be easier for them to help me up. The participants talked about their dependence on helpful nurses, but the tasks the nurses had to perform for them affected their daily life.

\section{Enjoying life}

Even though daily life for the old and chronically ill women and men meant being insufficient and dependent, it also had a more positive meaning, one described as enjoying life.

\section{Staying in their homes}

Enjoying life meant living at home; for some, it meant staying in a traditional home environment with the house redesigned and adapted to meet their needs. Ninety-four year old Linda said: So good ... you get help so that you can stay living at home as long as possible ... It is what's best after all. They were able to stay at home, but in an environment that had changed radically with the modern age in terms of socializing with neighbours and there being no shops in the neighbourhood.

Others had moved to sheltered housing where they had their own possessions, and the home was structured around the activities of daily life. They enjoyed the privacy of their own rooms, and their integrity remained intact. These older persons expressed satisfaction with this way of living; as 89-year old Harry said: I am very happy to live here ... They have everything here, even an alarm in case of emergency. They were able to live in these adapted homes because of the practical way in which they were set up, and they talked about the new opportunities for social interaction. All in all, they were provided with greater variety and opportunity.

The opportunity to continue to live at home could depend on access to facilities that helped older persons cope with everyday life. Some of the adaptations made to their homes were for practical purposes, while others helped them to feel safe. To improve safety, alarms had been installed. This, together with the confidence they had in the nurses, gave the interviewees a sense of security that enabled them to continue living at home. The facilities and modifications made for them helped to reduce their dependence on others, and their wish to remain at home was fulfilled by making a few adjustments.

\section{Feeling grateful}

Enjoying life could mean accepting the situation and feeling gratitude for the resources they still had. Accepting the situation was described by 89 -year old Carl as follows:

It is something I have been forced to accept ... you just have to get over it ... you try to sleep ... but can't always manage it ... you try. If you can't manage it, you just have to accept it.

Many things about their lives remained unchanged and thus had to be accepted in order for them to feel more positive about daily life.

Feeling grateful could mean thinking positively about getting up in the morning, having a family and happy memories, and simply being alive. Eighty-five year old Anna said: I have a lot to be grateful for ... and I live on that. I have a big box with only happy memories. I can just choose. Thinking positively about daily life was described by 94 -year old Linda as follows:

Both my hands are bad, but I get up in the morning and put my clothes on.

They were thankful for the resources they still had, which helped them feel a sense of control and gave them the opportunity to have contact with others.

\section{Feeling alive}

Enjoying life meant feeling alive by engaging with the world around them, reading newspapers, and following the news on television. TV provided them with the opportunity to become absorbed in programs on nature, political comment, and sports. Feeling alive could mean participation in activities they carried out alone as described by 91 -year old Phyllis:

... doing crossword puzzles. Then there are many things like, oh! ... finding the bay between this and that area, so then I have to look it up.

These activities demanded that they use a dictionary or atlas, which stimulated the mind and gave meaning to everyday life.

Some older persons participated in communal activities. Ninety-one year old Josephine described the importance of intellectual stimulation when she talked about her conversations with others: It's good because it means that something is moving up here Ipointing to her head]. The interviewees also described 
feeling alive as similar to enjoying springtime and the burgeoning of nature, and engaging in humor. Eighty-nine year old Carl said: Humor is something we have got to use ... I like humor. Yes, yes, that lightens up everyday life. A feeling of being alive kept them in good spirits.

\section{Comprehensive understanding}

Our interpretation suggested that daily life for oldest old persons and chronically ill persons meant days dominated by suffering, described in different ways such as illness, dysfunction, and limited energy. Being insufficient gave rise to feelings of asymmetric dependency on others. Daily life had its positive aspects, since the interviewees expressed that they were satisfied with their homes, and they had a will to live. On good days, they wanted to pursue activities, alone or in the company of others. Their dignity was threatened by feelings of being a burden to others. Dignity was affirmed by experiencing enjoyment of life and the search for meaning in it. ${ }^{32}$

\section{Discussion}

By illustrating the ways in which oldest old and chronically ill persons living at home experienced daily life, we interpreted suffering as based on feelings of insufficiency and dependency. Such suffering, however, could be contrasted with enjoying life, a feeling affirmed by continuing to live at home and being grateful, together with the feeling of being alive.

Home was a place of belonging, identity, and safety, as well as a place where the oldest old persons wanted to stay. ${ }^{9,10,41}$ Home had a central place in the lives of the oldest old persons,${ }^{13}$ who were satisfied with their sheltered housing. ${ }^{11,12}$ To be able to stay at home, our participants had made modifications for managing ADL functions in order to have a better life in terms of their chronic illness.

The participants felt ill with troublesome symptoms that needed consideration and treatment requiring a lot of organization. Kleinman ${ }^{18}$ differentiated between disease and illness. Illness could not be seen as independent of disease in this study, but rather in connection with it. Both perspectives were included in the totality of the individual's experiences. When illness was in the foreground, ${ }^{42}$ the participants had bad days because of the symptoms of their diseases, the treatments they received, and their limited energy. Other days, they were able to focus predominantly on their feeling of well-being. They looked forward to good days when they were in contact with others in the form of adapted activities. Enjoying life was affirmed by possessing a box of happy memories. Visits from friends and family, and being able to follow current affairs all contributed to living a good life. ${ }^{28}$ Activities like reading, listening to audio books, doing crossword puzzles, and making handicrafts were important. These activities demanded more time, attention, and concentration as the old people aged. ${ }^{43,44}$ For some, the ability to pursue these activities was lost. Focusing on symptom management and psychosocial and existential issues might be appropriate for the long-term care of older persons ${ }^{45}$ in order to balance illness and wellness when illness is chronic.

Delmar et $a l .{ }^{31}$ found that for a chronically ill person to be in harmony with him or herself, he or she had to accept life. Hope and enjoying life were closely interwoven and facilitated the phenomena in the process of becoming one-self. Enjoying life could be diminished by accident or illness, and then become more intense and clear. ${ }^{46,47}$ Our study showed that daily life was colored by both suffering and enjoyment, as these differed in determining bad days and good days. Enjoying life could balance opportunity and limited energy with qualities of resilience., ${ }^{5,23}$ This was a process of building up a feeling of being alive. ${ }^{48,49} \mathrm{Good}$ days helped them keep their spirits up and helped them to think positively when times were tough.

According to Frankl, ${ }^{32}$ when suffering cannot be changed, it has to be accepted and transformed into something meaningful. The participants accepted their situations by means of adaptation and adjustment, supported by family and home nursing care staff. Dependency involved a risk of their needs not being met or seen by the persons giving support and care. The help from home nursing care staff sometimes resulted in dependency that threatened the oldest old persons' dignity by objectifying them. Frank ${ }^{32}$ talks about two ways to define the meaning of life: love and suffering. Objectifying persons limited love and possibilities for relationships. In a good relationship and good dialogue, it is easier to look at oneself and understand one's own existence. The attributes for increasing the older person's feelings of dignity could be individualized care, respect, advocacy, and sensitive listening. ${ }^{50}$ Enjoying life, or the will to live, deals with the energy that is needed to live as a human and to take part in relationships with others. ${ }^{51}$ This might be affirmed by the feeling of inner strength. ${ }^{27,30}$ In this study, we found that positive relationships, activities, and dignity, as an inherent characteristic of being human, gave meaning to daily life.

\section{Limitations and implications}

This study focused on how these oldest old persons experienced daily life living with chronic illness. The strength of qualitative research is its flexibility and insight into complex phenomena, but it is limited by small samples and may not be generalized, as can quantitative data from a larger representative sample. Qualitative research is taking care of the situational context. ${ }^{52}$ In this study, the individuality of each person who participated in the study was important. It was also important not to make generalizations about the group of oldest old people.

It is for the readers of this research to judge how far our findings can be transferred to another context. To promote this, we have tried to give a detailed description of the study research context and methods, relying on our abilities as researchers to read and discuss the analysis.

Many of our respondents had limited capacity and we were unable to complete the interview in only one visit. One way to solve this was to continue the interview during another visit, particularly since the participants wanted the researcher to go back. It was felt that not doing this would deny them the opportunity to fully participate and have their voices heard.

Developing an understanding of the meaning of daily life for an older person living with chronic illness is important for the nursing profession in order to provide adequate health care. It is also important to have direct and efficient communication to respond to the issue of having the will to live, to support the opportunity to enjoy life, help the oldest old person to think positively in tough times, and to give each one a feeling of dignity.

There is concern that the busy daily schedule of the nurses has affected the quality of daily life for older persons, and this might thwart the process of empowering patients to have more control over living their lives free from attitudes of ageism, an attitude for which also the government is responsible. Further research needs to focus on the ways in which the nurse's busy schedule influences older persons in their daily life, and also on the best practices for caring for older persons with respect to their dignity, despite the priorities of the nurse's working day.

\section{Conclusions}

To illustrate the ways in which older and chronically ill persons experience the meaning of daily life, we found that the oldest old and chronically ill persons in this study had both positive and negative experiences. This study confirmed our existing knowledge about a person's inner strength and the will to live. Daily life provided our subjects with experiences of suffering and enjoying life that could help them meet adversity by way of qualities of resilience, thus giving them a meaningful 
daily life. The bad or good days they experienced depended not only on illness but also on the way in which the older persons' needs for help and support were met.

\section{References}

1. Schuurmans M. Older persons: the future of care. J Clin Nurs 2010;19:3274-90.

2. World Health Organization. Ageing and life course. http//www.who.int/ageing/index. html Accessed: 07.07.11.

3. Baltes PB, Smith J. New frontier in the future of aging: from successful aging of the young old to the dilemmas of the fourth age. Gerontology 2003;49:2:123-36.

4. Daatland SO, Herlofson K. Familie, velferdsstat og aldring. Familiesolidaritet i et europeisk perspektiv, NOVA-rapport 7/ 2004. Norsk institutt for forskning om oppvekst, velferd og aldring, Oslo, Norway; 2004.

5. Wagnild G, Young HM. Resilience among older women. IMAGE J Nurs Scholarship 1990;22:4:252-5.

6. Nygren B. Inner strength among the oldest old. A good aging. Umeå University, Medical Dissertations (Dept. Nursing). New series n. 1065, Umeå, Sweden; 2006.

7. Fisher RS. Living in consolation while growing very old. Umeå University Medical Dissertations (Dept. Nursing). New series n. 1087, Umeå, Sweden; 2007.

8. Meranius, MS. Era Delar är min helhet. Doctoral dissertation. Linnaeus University Dissertations n. 11/ 2010, Växjö, Sweden: 2010.

9. Moore J. Placing home in context. J Environ Psychol 2000;20:207-17.

10. Molony SL. The meaning of home. A gualitative metasynthesis. Res Gerontol Nurs 2010;3:4:291-307.

11. Field EM, Walker MH, Orrell MW. Social networks and health of older people living in sheltered housing. Aging Ment Health 2002;6:372-86

12. van Bilsen PMA, Hamers JPH, Groot W, Spreeuwenberg C. Sheltered housing compared to independent housing in the community. Scand J Caring Sci 2008;22:265-74.

13. Dahlin-Ivanoff S, Haak M, Fänge A, Iwarsson $\mathrm{S}$. The multiple meaning of home as the experienced by very old Swedish people. Scand J Occup Ther 2007;14:25-32.

14. Barnett M. Chronic obstructive pulmonary disease: a phenomenological study of patients' experiences. J Clin Nurs 2004;14:805-12.

15. Hornsten A, Lundman B, Selstam EK, Sandstrom H. Patient satisfaction with diabetes care. J Adv Nurs 2005;51:609-17.

16. Lütze U, Archenholtz B. The impact of arthritis on daily life with the patient per- spective in focus. Scan J Car Sc 2007;21:6470.

17. McEvoy P, Barnes P. Using the chronic care model to tackle depression among older adults who have long - term physical conditions. J Psychiatr Ment Hlt Nurs 2007;14: 233-8.

18. Kleiman A. The illness narrative. Suffering, healing and the human condition. Basic Book Inc. Publishers, New York, 1988.

19. Charmaz K. Loss of self: a fundamental form of suffering in the chronically ill. Sociol Health Ill 1983;5:168-94.

20. Heggdal K. Kroppskunnskaping: en grunnleggende prosess for mestring av kronisk sykdom. Institutt for samfunnsmedisinske fag, Section of Nursing Science. University of Bergen, Norway, 2003.

21. Lundman B, Jansson L. The meaning of living with a long-term disease. To revalue and be revalued. J Clin Nurs 2007;16:109-15.

22. Dyer JG, McGuinness TM. Resilience: analysis of the concept. Arch Psychiat Nurs 1996;X:276-82.

23. Staudinger UM, Marsiske M, Baltes PB. Resilience and levels of reserve capacity in later adulthood: perspectives from life-span theory. Dev Psychopathol 1993;5:541-66.

24. Hellström Y, Hallberg IR. Determinants and characteristics of help provision for elderly people living at home and in relation to quality of life. Scand J Car Sci 2004; 18:387-95.

25. Duggleby W, Holtslander L, Steeves M, Duggleby-Wenzel S. Discursive meaning of hope for older persons with advanced cancer and their caregivers. Can J Aging 2010;29:361-7.

26. Ferguson SJ, Goodwin AD. Optimism and well-being in older adults: the mediating role of social support and perceived control. Int $\mathrm{J}$ Aging Hum Dev 2010;71:43-68.

27. Nygren B, Alex L, Jonsén E, et al. Resilience, sense of coherence, purpose in life and selftransendence in relation to perceived physical and mental health among the oldest old. Age Ageing 2005;27: 23-33.

28. Andersson M, Hallberg IR, Edberg AK. Older people receiving municipal care, their experiences of what constitutes a good life in the last phase of life: a qualitative study. Int $\mathrm{J}$ Nurs Stud 2008:45:818-28.

29. Nilsson M, Ekman S-L, Sarvimäki A. Aging with joy or resigning to old age. Health Care Later Life 1998;3:94-110.

30. Katz J, Holland C, Peace S, Taylor E. A better life - what older people with high support needs value. The Joseph Rowntree Foundation, London, 2011.

31. Delmar C, Bøje T, Dylmer D, et al. Achieving harmony with oneself: life with a chronic illness. Scand J Car Sci 2005;19: 204-12.

32. Frankl V. Vilje til mening. Gyldendal, Oslo, Norway, 1971.

33. Ricoeur P. Interpretation theory. discourse and the surplus of meaning. Christian University Press, Forth Worth, TX, USA, 1976.

34. Husserl E. The idea of phenomenology. Nijhoff, The Hague, The Netherlands, 1966.

35. Ricoeur P. Hermeneutics and the human sciences. Cambridge University Press, UK, 1994.

36. Katz S. Assessing self-maintenance: activities of daily living, mobility, and instrumental activities of daily life. J Am Geriatr Soc 1983;31:721-7.

37. Lindset A, Norberg A. A phenomenological hermeneutical method for researching lived experience. Scand J Car Sci 2004;18: 145-53.

38. Patton MQ. Qualitative evaluations and research methods. 3rd ed. Newbury Park, CA, USA; Sage, London, UK, 2002.

39. Hellzén 0 . The meaning of being a carer for people with mental illness and provoking actions: careers' exposure in problematic care situations. Umeå University, Umeå, Medical Dissertations, Sweden, 2000.

40. Ricoeur P. From text to action. Essays in hermeneutics. Northwestern University Press, Evanston, Ill, USA, 1991.

41. Hammer RM. The lived experience of being at home. A phenomenological investigation. J Gerontol Nurs 1999;25:1.

42. Paterson BL. The shifting perspectives model of chronic illness. J Nurs Scholar-ship 2001;33:1:21-6.

43. Eloranta S, Routasalo P, Arve S. Personal resources supporting living at home as described by older home care clients. Int $\mathrm{J}$ Nurs Pract 2008;14:308-14.

44. Tollén A, Fredriksson C, Kamwendo K. Elderly persons with disabilities in Sweden: their experiences of everyday life. Occupat Ther Int 2008;15:133-49.

45. Hallberg IR. Palliative care as a framework for older people's long-term care. Int J Palliat Nurs 2006;12:5:224-9.

46. Pahuus M. Livet Selv. En livsfilosofisk tolkning af kristendommen. Philosophia, Århus, Denmark, 1993.

47. Delmar C. The phenomenology of life phenomena - in a nursing context. Nurs Philos 2006;7:235-46.

48. Jacelon CS. A concept analysis of dignity for older adults. J Adv Nurs 2004;48:76-83.

49. Delmar C, Bøje T, Dylmer D, et al. Independence/dependence - a contradictory relationship? Life with a chronic illness. Scand J Car Sci 2006;20:261-8.

50. Martinsen K. Fra Marx til Lögstrup: Om etikk og sannsynlighet i sykepleien. 2nd ed. Universitetsforlaget, Oslo, Norway, 2003.

51. Martinsen K. Samtalen, skjønnet og evidensen. Akribe, Oslo, Norway, 2005.

52. Polit DF, Beck CT. Nursing research. principles and methods. 7th ed. Lippincott Williams and Wilkins, Philadelphia, USA, 2004. 